complications caused by clinically unsuspected ingested dietary foreign bodies: a case series emphasizing the use of volume rendering techniques. Radiol Bras. 2013;46:346-50.

3. Tyng CJ, Bitencourt AGV, Almeida MFA, et al. Computed tomographyguided percutaneous biopsy of pancreatic masses using pneumodissection. Radiol Bras. 2013;46:139-42.

4. Elias Jr J. Imaging findings of unusual hepatic tumors: expanding the differential diagnosis. Radiol Bras. 2014;47(5):ix-x.

5. Silva EJC, Silva GAP. Local behavior and lymph node metastases of Wilms' tumor: accuracy of computed tomography. Radiol Bras. 2014; 47:9-13.

6. Torres LR, Timbó LS, Ribeiro CMF, et al. Multifocal and metastatic hepatic hemangioendothelioma: case report and literature review. Radiol Bras. 2014;47:194-6.

7. Pedrassa BC, Rocha EL, Kierszenbaum ML, et al. Uncommon hepatic tumors: iconographic essay - Part 1. Radiol Bras. 2014;47:310-6.

8. Pedrassa BC, Rocha EL, Kierszenbaum ML, et al. Uncommon hepatic tumors: iconographic essay - Part 2. Radiol Bras. 2014;47:374-9.
9. Jung SE, Lee JM, Rha SE, et al. CT and MR imaging of ovarian tumors with emphasis on differential diagnosis. Radiographics. 2002;22:130525.

10. Park SB, Kim JK, Kim KR, et al. Imaging findings of complications and unusual manifestations of ovarian teratomas. Radiographics. 2008; 28:969-83.

11. Outwater EK, Siegelman ES, Hunt JL. Ovarian teratomas: tumor types and imaging characteristics. Radiographics. 2001;21:47590.

Thiago Krieger Bento da Silva ${ }^{1}$, Guilherme Jaquet Ribeiro ${ }^{1}$, Felipe Alba Scortegagna ${ }^{1}$, Gláucia Zanetti ${ }^{2}$, Edson Marchiori ${ }^{2}$

1. Department of Radiology, Hospital São Lucas - Pontifícia Universidade Católica do Rio Grande do Sul (PUCRS), Porto Alegre, RS, Brazil. 2. Department of Radiology, Faculty of Medicine, Universidade Federal do Rio de Janeiro (UFRJ), Rio de Janeiro, RJ, Brazil. Mailing Address: Dr. Edson Marchiori. Rua Thomaz Cameron, 438, Valparaíso. Petrópolis, RJ, Brazil, $25685-$ 120. E-mail: edmarchiori@gmail.com.

http://dx.doi.org/10.1590/0100-3984.2015.0034

\section{Dactylolysis spontanea (ainhum)}

Dactilose espontânea (ainhum)

\section{Dear Editor,}

A 76-year-old, white woman presenting with bone resorption in the fifth toes. For three years, the patient had experienced severe pain and local edema. Conventional radiography (Figure 1) demonstrated narrowing and osteolysis of the middle and distal phalanges of the fifth toes, most noticeable at left, in association with focal and concentric decrease in the soft parts thickness at the roots of those toes. Because of the intense local pain, the patient underwent surgical amputation of the fifth toes, and the symptoms disappeared.

Several spontaneously painful conditions of lower and upper limbs, particularly in their extremities, have been observed and reported in Brazil ${ }^{(1-5)}$.

Dactylolysis spontanea (DS), that is also known as "ainhum", is a rare disease occurring principally in Afrodescendant male individuals (2:1) aged between 30 and 50 ${ }^{(6)}$. "Ainhum" is an Angolan

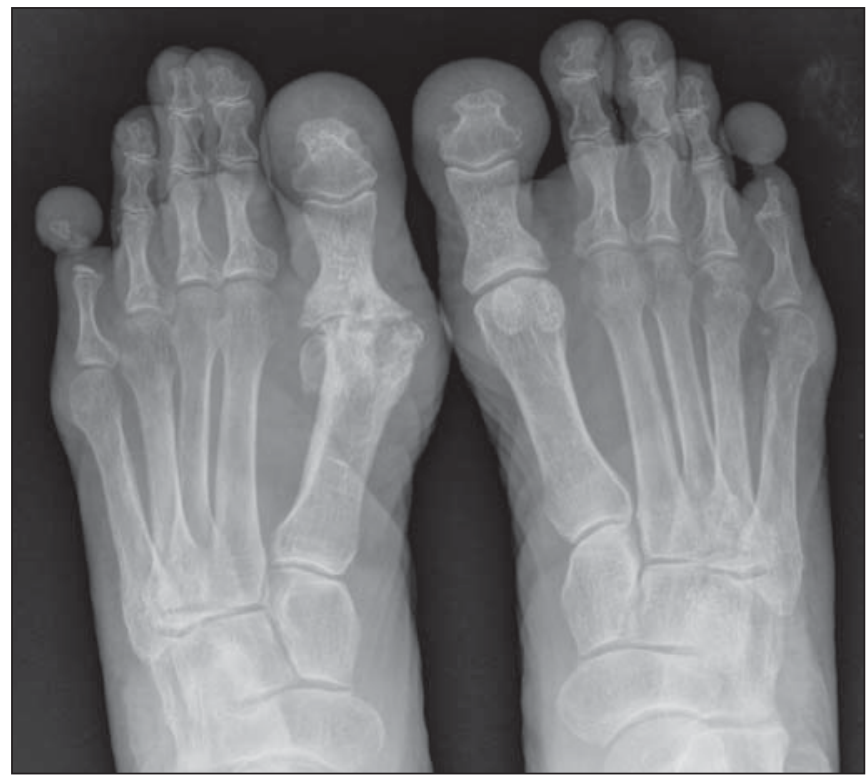

Figure 1. Radiography - anteroposterior view of the feet two years after the symptoms onset. In addition to the narrowing and osteolysis of the fifth middle and distal phalanges, particularly at left, incidental degenerative diseases are observed in the metatarsal phalangeal joint of the right hallux. word meaning "to saw". The first case report of DS in Brazil refers to a "quilombola" in Bahia state and was described by Silva Lima in $1867^{(7)}$. The prevalence of DS ranges from 0.015 to $2 \%$ of the population in African countries. In Brazil, its prevalence is still to be studied.

Few reports of cases of DS in white individuals are found in the literature ${ }^{(8)}$. In Brazil, due to ethnic miscegenation, a higher incidence of this disease may be observed in white individuals with some African ancestry that is not always noticeable in their phenotype.

The main DS feature of this condition is the development of a fibrotic constriction ring involving the base of one or more toes, conditioning eversion and absorption of distal structures, possibly progressing to spontaneous amputation ${ }^{(9)}$. Recently a case of DS involving toes and fingers was reported ${ }^{(9)}$.

The radiographic findings are typical and may be classified into four phases, as follows: the first one is characterized by the development of a deep sulcus along the medial aspect of the distal portion of the proximal phalanx, sometimes resembling the shape of a sand glass. The second phase progresses with increase in the volume distally to the constriction ring, secondary to lymphedema. The third phase is characterized by progressive bone absorption, and the fourth phase, by spontaneous amputation averagely occurring within fourth to six years after the disease onset ${ }^{(9)}$.

The differential diagnosis should be made with other conditions involving the development of fibrotic constriction rings such as porokeratosis of Mibelli; erythropoietic protoporphyria; scleroderma; psoriasis; neuropathic plica; hanseniasis; syphilis; Raynaud's disease; diabetes mellitus and syringomyelia. Also, facticious pseudoainhum, caused by hair-thread tourniquet syndrome should be considered ${ }^{(9)}$.

No well established treatment for DS is available yet. Resection of the sulcus followed by z-plasty may alleviate the pain and avoid spontaneous amputation at early stages of the disease ${ }^{(6)}$. Surgical amputation may be recommended to alleviate the symptoms ${ }^{(10)}$.

DS is a rare disease whose diagnosis is hampered by its low prevalence and variable clinical presentation. The radiological evaluation allows for an early diagnosis, preventing spontaneous amputation.

\section{REFERENCES}

1. Machado BB, Lima CMAO, Junqueira FP, et al. Magnetic resonance imaging in intersection syndrome of the forearm: iconographic essay. Radiol Bras. 2013;46:117-21. 
2. Silveira RB, Lopes FAR, Reis ALB, et al. Dysplasia epiphysealis hemimelica (Trevor-Fairbank disease): case report. Radiol Bras. 2013;46: 59-60.

3. Alves MPT, Fonseca COP, Granjeiro JM, et al. Carpal tunnel syndrome: comparative study between sonographic and surgical measurements of the median nerve in moderate and severe cases of disease. Radiol Bras. $2013 ; 46: 23-9$.

4. Bayerl JS, Oliveira ARN, Peçanha PM, et al. Osteomyelitis of the wrist in a patient with disseminated paracoccidioidomycosis: a rare presentation. Radiol Bras. 2012;45:238-40.

5. Arend CF. Tenosynovitis and synovitis of the first extensor compartment of the wrist: what sonographers should know. Radiol Bras. 2012;45:21924.

6. Tyring SK, Lupi O, Hengge UR. Tropical dermatology. 1st ed. Georgetown: Landes Bioscience; 2001.

7. Silva Lima JF. Ainhum. Molestia ainda não descripta, peculiar à raça ethiopica e affectando os dedos mínimos dos pés. Gaz Med Bahia. $1867 ; 2: 146-72$
8. Bertoli CL, Stassi J, Rifkin MD. Ainhum - an unusual presentation involving the second toe in a white male. Skeletal Radiol. 1984;11:133-5.

9. de Araujo DB, Lima SM, Giorgi RD, et al. Ainhum (dactylolysis spontanea): a case with hands and feet involvement. J Clin Rheumatol. 2013 19:277-9

10. Olivieri I, Piccirillo A, Scarano E, et al. Dactylolysis spontanea or ainhum involving the big toe. J Rheumatol. 2005;32:2437-9.

\section{Ronaldo Garcia Rondina ${ }^{1}$, Ricardo Andrade Fernandes de Mello $^{1}$, Gabriel Antônio de Oliveira ${ }^{1}$, Laís Bastos Pessanha $^{1}$, Luiz Felipe Alves Guerra ${ }^{1}$, Diego Lima Nava Martins $^{1}$}

1. Universidade Federal do Espírito Santo, Vitória, ES, Brazil. Mailing Address: Dr. Ronaldo Garcia Rondina. Rua Júlio Cesar de Oliveira Serrano, 135, ap. 302, Bloco 03, Mata da Praia. Vitória, ES, Brazil, 29065-720. E-mail: r.rondina@gmail.com.

http://dx.doi.org/10.1590/0100-3984.2014.0064

\section{Uncommon presentation of perforated Meckel's diverticulum in preterm newborn}

Divertículo de Meckel perfurado como causa incomum de pneumoperitônio em recém-nascido pré-termo

Dear Editor,

A male neonate with gestational age of 30 weeks, weighting $940 \mathrm{~g}$ at birth, with respiratory failure right after birth, and radiological signs compatible with hyaline membrane disease. At his tenth day of life, the patient presented vomiting and abdominal distention, presenting with radiological signs of pneumoperitoneum (Figure 1).

Initially, the neonate was submitted to peritoneal drainage, due to the lack of surgical conditions, and at the 19th day, after gaining weight and present with hemodynamically stable conditions, was submitted to exploratory laparotomy. During the surgery, a Meckel's diverticulum (MD) was found, with jejunal perforation, hepatic blockage and obstruction distal to the blockage due to the development of adherence. Resection of about $6 \mathrm{~cm}$ of the jejunal loop including the perforated area was performed, with later termino-terminal anastomosis. The anatomopathological result was subacute diverticulitis with ulcer and severe peridiverticulitis. The neonate presented a favorable evolution and was discharged at his 82 nd day of life.

Meckel's diverticulum represents the most common congenital malformation of the digestive tube, and is asymptomatic in most cases ${ }^{(1-3)}$. Symptomatic cases of MD are rarely found, affecting less than $20 \%$ of all pediatric cases ${ }^{(1)}$. Bowel obstruction

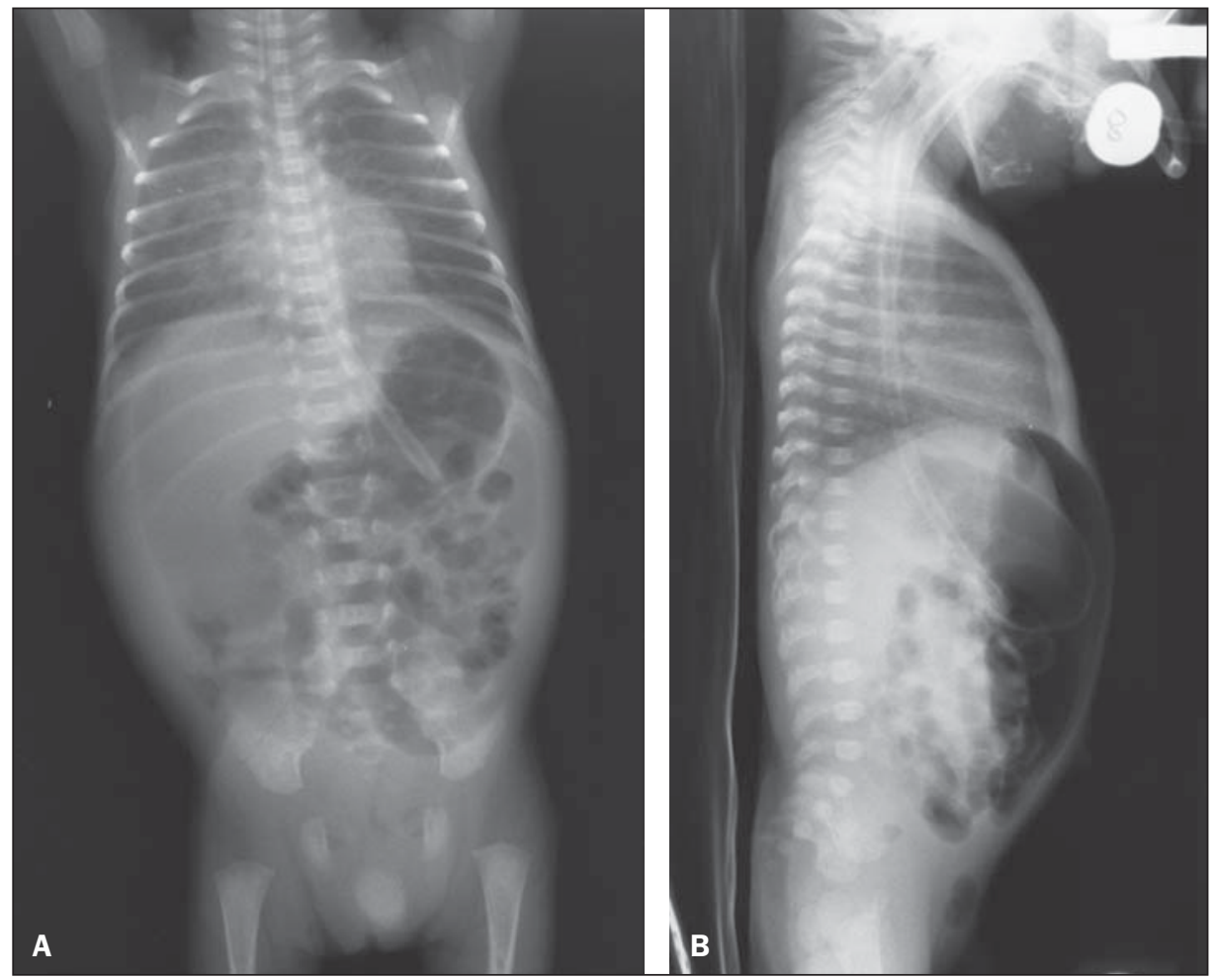

Figure 1. A: Chest and abdominal radiography - Image acquired with the patients in supine position, with vertical x-rays, demonstrating hypertransparent abdominal cavity due to accumulation of free air. B: Chest and abdominal radiography - Image acquired with the patient in supine position with horizontal x-rays, demonstrating the free air collection located between the anterior abdominal wall and the bowel loops. 